\title{
Zanahoria amarilla (Daucus carota $L$.) como alimento biotecnológico para vacas
}

\section{Yellow carrot (Daucus carota L.), a biotechnological food for cows}

Fecha de recepción: 1 de abril de 2018

Fecha de aprobación: 6 de junio de 2018
Byron Díaz-Monroy ${ }^{1}$

Elvita Chacha²

Fernanda Baquero ${ }^{3}$

DOI: http://doi.org/10.19053/01228420.v15.n2.2018.8442

\section{Resumen}

Se evaluaron residuos agroindustriales de zanahoria con suero de leche para elaborar bioensilaje para vacas. Se efectuaron análisis físicos, bromatológicos y microbiológicos. Se utilizaron cuatro tratamientos (diferentes concentraciones de preparado microbiano nativo-probiótico), con $2 \%, 4 \%, 6 \%$ y $8 \%$. El pH del proceso fue 3,9 , y la temperatura, $19{ }^{\circ} \mathrm{C}$. El tratamiento con $6 \%$ de probiótico obtuvo los mejores resultados, con 15,39\% de proteína, 74,78\% de humedad y 14,04\% de fibra, libre de patógenos como Salmonella sp., Clostridium sp., Escherichia coli y mohos; con una mayor concentración de bacterias ácido-lácticas $\left(2,40 \mathrm{E}+04\right.$ UFC. $\left.\mathrm{ml}^{-1}\right)$ y un beneficio costo de 1,33. La producción de leche en vacas Holstein

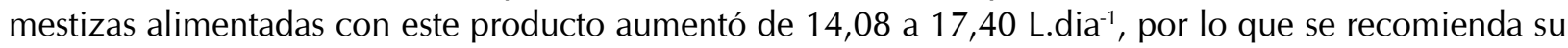
uso como alimento suplementario.

Palabras clave: bacterias ácido-lácticas; bioensilaje; fermentación sólida; probiótico.

\begin{abstract}
1 Ph.D. Escuela Superior Politécnica de Chimborazo (Riobamba, Ecuador).

2 Escuela Superior Politécnica de Chimborazo (Riobamba, Ecuador).

3 Universidad Nacional de Chimborazo (Riobamba, Ecuador).
\end{abstract}

Agro-industrial residues of carrots along with whey were evaluated and used to prepare bio-silage for cows. Physical, bromatological and microbiological analyzes were carried out. Four treatments (different concentrations of native-probiotic microbial preparation) were used with $2 \%, 4 \%, 6 \%$, and $8 \%$. The pH of the process was 3.9 and the temperature was $19{ }^{\circ} \mathrm{C}$. The treatment with $6 \%$ of probiotic yielded the best results, with $15.39 \%$ of protein, $74.78 \%$ of humidity and $14.04 \%$ of fiber, free of pathogens like SalmoneIla sp., Clostridium sp., Escherichia coli and molds, with and a high concentration of lactic acid bacteria

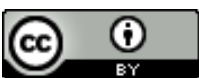


$\left(2.40 \mathrm{E}+04\right.$ UFC. $\left.\mathrm{ml}^{-1}\right)$ and a cost benefit of 1.33. Milk production in crossbred Holstein cows fed with this product increased from 14.08 to $17.40 \mathrm{~L} . d a y^{-1}$, so we recommended using it as supplementary feed.

Keywords: bio silage; lactic acid bacteria; probiotic; solid fermentation.

\section{Para citar este artículo:}

Díaz-Monroy B., Chacha E., Baquero F. Zanahoria amarilla (Daucus carota L.) como alimento biotecnológico para vacas. Ciencia y Agricultura. 2018; 15(2): 83-97. 


\section{Introducción}

El cultivo de zanahoria en el Ecuador ocupa una superficie mayor a las 4000 ha; entre las principales provincias productoras se encuentran Pichincha, con 870 ha; Bolívar, con 480 ha; Cotopaxi, con 446 ha, y Chimborazo, con 1350 ha sembradas (1).

En cuanto a la producción de leche, la región Sierra es la que más aporta, con el 75,9\%, seguida de la Costa, con el 16,6\%, y el Oriente, con el 7,6\%. También, según el promedio de litros de leche por vaca producidos, la región que más se destaca es la Sierra, con 6,7 L/vaca, debido, principalmente, a la gran cantidad de ganado lechero presente y a los pastos cultivados y naturales que sirven para su alimentación; la región Oriental ocupa el segundo lugar, con 4,7 L/vaca, y, por último, la región Costa, con 3,6 L/vaca (2). Chimborazo es la provincia más lechera de todo el grupo; según el Censo Nacional Agropecuario, realizado en el año 2000, se producen en la provincia 131459 litros de leche diariamente.

Estas actividades agroindustriales, por procesos aplicados y por pérdidas poscosecha, generan en el Ecuador miles de toneladas de residuos, cuya cifra exacta no se ha determinado. Estos desechos no son aprovechados eficientemente, en parte, porque su valor es aún desconocido y, sobre todo, por la falta de métodos apropiados para preparar y caracterizar sustancias de mayor valor agregado con la suficiente calidad e inocuidad como para ser usadas en procesos alimenticios. Algunos de los residuos son arrojados a vertederos a cielo abierto, convirtiéndose en focos de contaminación, por su elevado contenido de materia orgánica.

Los desechos generados son, principalmente, residuos de camales, suero de leche (185 toneladas métricas al año, según datos del Ministerio de Industrias y Productividad) y desechos agrícolas. Dentro de los desechos agrícolas, según el Ministerio de Agricultura del Ecuador, se generaron en el año 2013 unas 344418 toneladas métricas de cascarilla de arroz, 57020 toneladas métricas de residuos de la cosecha de zanahoria y 1043 toneladas métricas de cáscara de trigo, además de desechos de industrias de pulpas y mermeladas, los cuales generan anualmente $281 \mathrm{~m}^{3}$ por tonelada de materia prima. Estos subproductos representan un importante problema ambiental para los productores, pues afectan tanto la calidad del ambiente como la economía local, generando considerables gastos económicos orientados a minimizar sus efectos.

Enmarcados en el Plan del Buen Vivir del Ecuador, que en el objetivo siete manifiesta "Garantizar los derechos de la naturaleza y promover la sostenibilidad ambiental territorial y global", es evidente la necesidad de utilizar los residuos mediante alternativas tecnológicas disponibles a través de la biotecnología, como el uso de microorganismos benéficos, las cuales nos permiten aprovecharlos en la generación de alimentos con características adecuadas para rumiantes. Con esta tecnología, los pequeños, medianos y grandes productores agroindustriales pueden aprovechar sus residuos, ya que se les genera una alternativa de uso que les posibilita obtener ingresos económicos y disminuir el impacto ambiental; del mismo modo que los ganaderos dispondrían de un producto alimenticio sano y nutritivo elaborado a base de residuos para sus semovientes, con lo cual los dos sectores citados contribuirían a la economía del país.

De esta manera, se plantearon estos objetivos: 1) Clasificar y caracterizar los residuales de cosecha de la zanahoria amarilla y del suero de leche, 2) Desarrollar una tecnología basada en la fermentación sólida para aprovechar los residuales en un proceso de bioensilaje, 3) Determinar las características y bondades del producto obtenido como alimento para rumiantes y 4) Calcular el beneficio costo de esta tecnología.

\section{Materiales y métodos}

La investigación se realizó en el Laboratorio de Biotecnología y Microbiología animal (LABIMA) y en la Estación Experimental Tunshi de la Escuela Superior Politécnica de Chimborazo, Riobamba, Ecuador, ubicada a una altitud de 2754 m s.n.m. y con condiciones meteorológicas que se exponen en la Tabla I. 
Tabla I. Condiciones meteorológicas de sitio

\begin{tabular}{|c|c|}
\hline Parámetro & Promedio \\
\hline Temperatura & $14,35^{\circ} \mathrm{C}$ \\
\hline Humedad relativa & $61,40 \%$ \\
\hline Precipitación & $428 \mathrm{~mm}$ \\
\hline
\end{tabular}

Fuente: Estación Meteorológica ESPOCH (2015)

\section{A. Tratamientos}

Los tratamientos fueron distribuidos bajo un diseño Completamente al Azar, y se estructuraron como consta en la Tabla II:

Tabla II. Esquema del experimento laboratorio

\begin{tabular}{|c|c|c|c|c|}
\hline $\begin{array}{c}\text { Tratamientos } \\
\text { (Nivel probiótico \%) }\end{array}$ & Código & Repeticiones & TUE* & Total \\
\hline 2 & T1 & 4 & 1 & 4 \\
\hline 4 & T2 & 4 & 1 & 4 \\
\hline 6 & T3 & 4 & 1 & 4 \\
\hline 8 & T4 & 4 & 1 & 4 \\
\hline Total & & & & 16 \\
\hline
\end{tabular}

TUE: Tamaño de unidades experimental (ensilaje) en kg

B. Escalado del ensilaje para la alimentación de vacas

Se realizaron cinco silos, considerando los cuatro tratamientos con los diferentes niveles de probiótico $(2,4,6$ y $8 \%$ ) y un control, o testigo, sin probiótico, de $50 \mathrm{~kg}$ cada uno, que contuvieron zanahoria en raíz y follaje y afrecho de trigo, según la composición que se indica en la Tabla IV. Este producto fue evaluado en 10 vacas de la Estación Experimental Tunshi, escogidas al azar; estableciéndose dos semovientes para cada tratamiento (Tabla III).

Tabla III. Esquema del experimento para alimentación de vacas con el ensilaje

\begin{tabular}{|c|c|c|c|c|}
\hline $\begin{array}{c}\text { Tratamientos } \\
\left(\begin{array}{c}\text { Nivel probiótico } \\
\%)\end{array}\right.\end{array}$ & Código & Repeticiones & TUE & Total \\
\hline 0 & T0 & 2 & 1 & 2 \\
\hline 2 & T1 & 2 & 1 & 2 \\
\hline 4 & T2 & 2 & 1 & 2 \\
\hline 6 & T3 & 2 & 1 & 2 \\
\hline 8 & T4 & 2 & 1 & 2 \\
\hline Total & & & & 10 \\
\hline
\end{tabular}

TUE: Tamaño de unidades experimental, expresado en número de vacas 


\section{Preparado microbiano nativo (probiótico)}

Se utilizó un preparado microbiano nativo (probiótico) caracterizado en una investigación previa (3). Se emplearon como ingredientes: suero de leche, sal mineral, jugo de caña, yogurt natural, sulfato de amonio, urea y agua, los cuales se mezclaron en envases plásticos de $4 \mathrm{~L}$; esta preparación permaneció durante 48 a 72 horas a temperatura ambiente ( $14{ }^{\circ} \mathrm{C}$ promedio en Riobamba), produciéndose una fermentación ácida, predominantemente láctica.

\section{Residuos de zanahoria}

Los residuos de zanahoria se obtuvieron del centro de acopio Mercado Mayorista de la ciudad de Riobamba, generados por los comerciantes de dicho lugar, y el bioensilaje se elaboró picando la zanahoria y el follaje a un grosor no mayor a $2 \mathrm{~cm}$, para asegurar su compactación posterior; luego, se mezcló con el afrecho y el probiótico, en cantidades que constan en la Tabla IV, se depositó en fundas negras de polietileno y se compactó, y las fundas se sellaron herméticamente, para evitar la proliferación de microorganismos indeseados.

Tabla IV. Composición del bioensilaje

\begin{tabular}{|c|c|c|c|}
\hline $\begin{array}{c}\text { ZANAHORIA } \\
(\text { RAÍZ) }\end{array}$ & $\begin{array}{c}\text { FOLLAJE } \\
\text { DE ZANAHORIA }\end{array}$ & $\begin{array}{c}\text { AFRECHO DE } \\
\text { TRIGO }\end{array}$ & NIVELES DE PROBIÓTICO \\
\hline $60 \%$ & $20 \%$ & DEL $12 \mathrm{AL} 18 \%$ & SEGÚN EL TRATAMIENTO $(2,4,6$, y $8 \%)$ \\
\hline
\end{tabular}

\section{E. Indicadores determinados}

Con la aplicación de técnicas y métodos estándares de laboratorio se determinó:

$\checkmark \quad$ La calidad nutritiva de los residuos utilizados (humedad, materia seca, fibra y proteína bruta) (4).

$\checkmark \quad$ La calidad del producto terminado: humedad, materia seca, fibra y proteína bruta (4), bacterias ácido-lácticas mediante siembra en agar MRS (Man, Rogosa y Sharpe); hongos, Salmonella sp., Clostridium sp. y E. coli (5), $\mathrm{pH}$ y temperatura.

$\checkmark \quad$ El costo. $\mathrm{kg}^{-1}$ de producto.

\section{F. Suministro del bioensilaje al ganado durante la prueba biológica de aceptabilidad}

La selección y agrupamiento de las 10 vacas para el ensayo se realizó teniendo en cuenta el núme- ro de partos, y se distribuyeron dos por cada tratamiento. Una ración individual de $3 \mathrm{~kg}$.día ${ }^{-1}$ de bioensilaje se les ofreció en el momento del ordeño. La producción de leche se registró diariamente en los dos ordeños (mañana y tarde).

\section{Resultados y discusión}

\section{A. Características bromatológicas de la materia prima}

En la Tabla $V$ se observan los resultados del análisis bromatológico de la zanahoria y su follaje. La cantidad de proteína y humedad disminuye a medida que la planta se desarrolla o envejece, tomando en consideración que este fenómeno es menor en leguminosas y tubérculos, en comparación con gramíneas (6). En un estudio de características parecidas se reportan valores similares para humedad y proteína: $90 \%$ y 6,9\%, respectivamente (1). En suelos con altos contenidos en nitrógeno se eleva el contenido proteico en el follaje de las plantas que allí crecen (6). 
Tabla V. Resultados del análisis bromatológico de la zanahoria y su follaje

\begin{tabular}{|c|c|c|}
\hline INDICADOR & ZANAHORIA (\%) & FOLLAJE (\%) \\
\hline HUMEDAD & 90,20 & 83,51 \\
\hline MATERIA SECA & 9,80 & 16,49 \\
\hline PROTEÍNA & 7,16 & 10,53 \\
\hline FIBRA & 7,40 & 14,74 \\
\hline
\end{tabular}

Tabla VI. Resultados del análisis del suero de leche

\begin{tabular}{|c|c|}
\hline Indicador & Resultado \\
\hline $\mathrm{pH}$ & 6,5 \\
\hline Proteína & $0,7 \%$ \\
\hline Grasa & $0,55 \%$ \\
\hline Cenizas & $0,5 \%$ \\
\hline
\end{tabular}

La calidad del suero está relacionada directamente con la calidad de la leche que ha sido procesada en la industria del queso. Son diversos los factores que afectan la calidad nutricional de la leche, como la composición de la dieta, el clima, la etapa de lactancia, la genética, etc.; factores que de forma individual o conjunta determinan el volumen y la concentración de componentes lácteos como proteína y grasa (7). En Ecuador, los niveles de proteína para la leche de vaca se encuentran alrededor del 3,5\%, y los de grasa, en el 3,7\% (8). Se reportan valores de 5,6 para el $\mathrm{pH}, 0,93 \%$ para la proteína, 0,80\% para grasa y $0,62 \%$ para las cenizas, para un suero de este tipo (9); valores que resultan ser superiores a los de la presente investigación. Por otro lado (10), se presentan valores para grasa del $0,5 \%$ y proteína del $0,60 \%$, los cuales son inferiores a los reportados en este ensayo.

\section{B. Análisis físico-químico del ensilaje}

Los grados Brix (Figura 1) miden la cantidad de sacarosa presente en una solución; representan el porcentaje de sólidos solubles; en el refractómetro son determinado por el índice de refracción que da una dilución de sacarosa al 1\% (10). El probiótico inicia con $6^{\circ} \mathrm{B}$, a las 24 horas baja a $5,8^{\circ} \mathrm{B}$ y, finalmente, a las 96 horas alcanza un valor de 5,4 ${ }^{\circ} \mathrm{B}$; así, el probiótico se considera bajo en azúcares.

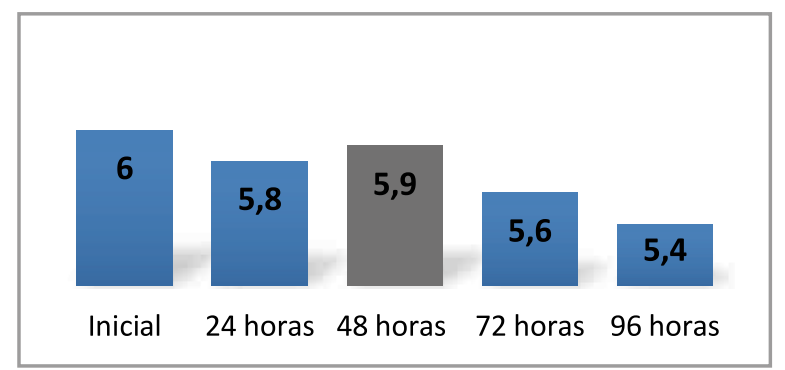

Figura 1. Grados Brix del probiótico

El bioensilaje puede mantener sus características y cualidades a un $\mathrm{pH}$ menor a 4,2; sin embargo, valores de 5,0 son aceptables, siempre que exista una proporción elevada de materia seca (11). Si el silo fue mal tapado y su compactación fue mala y entra oxígeno, se generan pérdidas de materia seca $y$, por ende, un aumento en la temperatura; la temperatura óptima para un ensilaje está entre $20{ }^{\circ} \mathrm{C}$ y $39{ }^{\circ} \mathrm{C}$ para el crecimiento de las bacterias ácido-lácticas, cuyo crecimiento cesa a los $50^{\circ} \mathrm{C}$ (Tabla VII).

Tabla VII. $\mathrm{pH}$ y temperatura para el bioensilaje de zanahoria

\begin{tabular}{|c|c|c|c|}
\hline Indicador & Inicial & 12 días & 24 días \\
\hline $\mathrm{pH}$ & 6,0 & 3,7 & 3,9 \\
\hline Temperatura $\left({ }^{\circ} \mathrm{C}\right)$ & 22 & 20 & 19 \\
\hline
\end{tabular}


En el trabajo de investigación previo se obtuvieron valores de $\mathrm{pH}$ de $4,45,4,55$ y 4,6 (12), superiores a los de esta investigación, lo cual puede deberse al contenido del inoculante aplicado en estas investigaciones. En cuanto a temperatura, obtienen valores de $21{ }^{\circ} \mathrm{C}, 22{ }^{\circ} \mathrm{C}$ y $23{ }^{\circ} \mathrm{C}$, que son superiores a las del presente ensayo, lo cual puede ser por el sellado, su compactación, las condiciones de fermentación o, inclusive, por el contenido en el inoculante.

\section{Características bromatológicas del ensilaje}

Para la variable humedad se reportaron diferencias estadísticas altamente significativas $(P<0,01)$; el mayor porcentaje de humedad se presentó al usar el $6 \%$ de probiótico nativo, con $74,78 \%$, y desciende a $73,27 \%, 73,04 \%$ y $72,97 \%$ con los niveles de $8 \%, 4 \%$ y $2 \%$ (Figura 3 ). Quizás esto se vea influenciado por la actividad microbiana, tomando en consideración que, como lo sustentan Jiménez y Moreno (11), a mayor porcentaje de humedad del ensilaje y $\mathrm{pH}$ alto se desarrollan bacterias indeseables del género Clostridium, las cuales producen ácido butírico, amoniaco y aminas, que son particularidades de la materia orgánica en descomposición, lo cual genera un ensilaje de mala calidad. El crecimiento de estos microorganismos se inhibe disminuyendo la humedad a menos del $70 \%$ o subiendo la acidez (Tabla VIII).

Tabla VIII. Análisis bromatológicos del bioensilaje

\begin{tabular}{|c|c|c|c|c|c|c|c|c|c|}
\hline \multicolumn{10}{|c|}{ Niveles de probiótico, \% } \\
\hline Variable & 2 & & 4 & & 6 & & 8 & E.E. & Prob. \\
\hline Humedad, \% & 72,97 & $b$ & 73,04 & $\mathrm{~b}$ & 74,78 & $\mathrm{a}$ & $73,27 \quad b$ & 0,10 & 0,0006 \\
\hline Materia seca, \% & 27,03 & a & 26,97 & $\mathrm{a}$ & 25,22 & $\mathrm{~b}$ & 26,74 a & 0,10 & 0,0006 \\
\hline Proteína, \% & 14,01 & C & 14,79 & $\mathrm{~b}$ & 15,39 & $\mathrm{a}$ & 14,53 bc & 0,10 & 0,0002 \\
\hline Fibra, \% & 13,66 & $\mathrm{a}$ & 12,29 & $\mathrm{~b}$ & 14,04 & $\mathrm{a}$ & $12,42 \quad b$ & 0,12 & 0,0011 \\
\hline
\end{tabular}

Letras diferentes muestran diferencias estadísticas entre las medias (Tukey $\leq 0,05$ )

En el trabajo de Ruiz (13) se obtuvo un contenido de humedad en el bioensilaje del $71,67 \%$, valor inferior a los de la presente investigación; quizá esto se deba a que la zanahoria tiene alto contenido de humedad, mientras que la papa contiene almidón, que puede actuar durante el proceso disminuyendo el nivel de humedad en la composición. Mientras que en otra investigación se alcanzó un mayor contenido de humedad, con 73,9 \%, al emplear diferentes cantidades de residuos de lechuga con inóculos de suero de leche para la fabricación de un bioensilaje (14), valor que guardan relación con los datos reportados en la presente investigación; posiblemente esto se deba al alto contenido de humedad de las materias primas manejadas en las dos investigaciones, ya que estas hortalizas contienen del $92 \%$ al $94 \%$ de humedad (15). En la Figura 2 se observa el análisis de regresión para la variable humedad al utilizar diferentes niveles de probiótico.

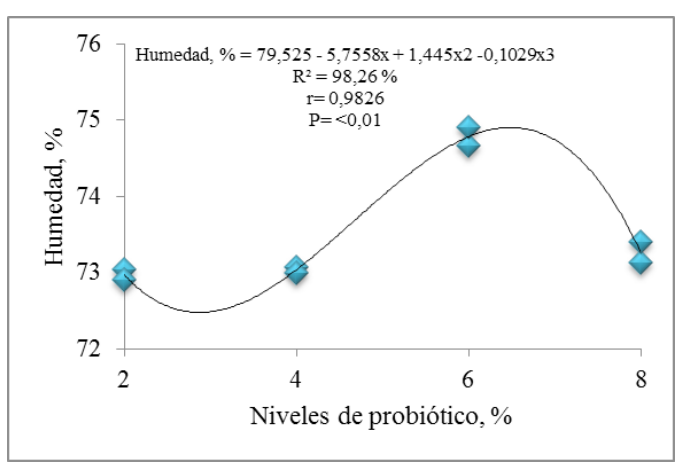

Fig. 2. Análisis de regresión para la humedad.

En el análisis del indicador "materia seca" se reportaron diferencias altamente significativas $(P<0,01)$. El mayor contenido de materia seca se reportó en el ensilaje con el $2 \%$ de probiótico, con un valor de $27,03 \%$, y el menor, en los ensilajes con el $4 \%, 6 \%$ y $8 \%$ de probiótico, con medias de $26,97,25,22$ y $26,74 \%$, respectivamente. Esto sugiere que la cantidad de materia seca podría no estar influenciada por el porcentaje de probiótico 
utilizado en el ensilaje y por el alto contenido de humedad de la materia prima utilizada.

En otraa investigación se obtuvo un porcentaje de materia seca del $31,14 \%$ (16), valor que es superior a los obtenidos en la presente investigación; se puede decir que esto se debe a la cantidad de humedad que contiene la materia prima utilizada, ya que la zanahoria contiene un alto porcentaje de humedad, como se mencionó, mientras que el maíz forrajero presenta una humedad inferior, de $73,58 \%$, alterando de esta manera el contenido de los bioensilajes evaluados. En la Figura 3 se observa el análisis de regresión para la variable materia seca, utilizando diferentes niveles de probiótico.

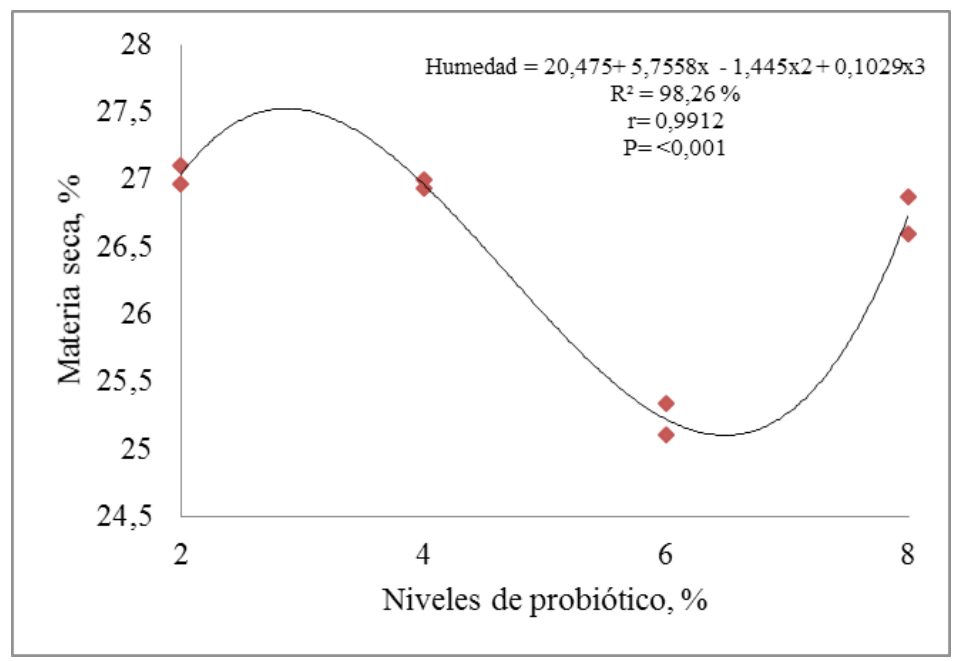

Fig. 3. Análisis de regresión para la materia seca.

En el análisis estadístico para la variable contenido de proteína en el bioensilaje para rumiantes se encontraron diferencias estadísticas altamente significativas $(P<0,01)$. El mayor valor proteico fue del $15,39 \%$, alcanzado en el tratamiento con el $6 \%$ del probiótico, y descendió con los tratamientos del $4 \%$, el $8 \%$ y el $2 \%$ de probiótico, con medias de $14,79 \%, 14,53 \%$ y $14,01 \%$, respectivamente, con una desviación entre medias de \pm de 0,10.

El tratamiento con el $6 \%$ de probiótico tiene el valor más alto de proteína, con lo cual la producción de leche aumenta; se asume que la cantidad de nitrógeno o contenido proteico en rumiantes lactantes se considera, en general, un aporte proteico del $16 \%$, el mismo que se verá alterado por aspectos como edad y etapa fisiológica de los animales; además, se puede acotar que la proteína de los alimentos no solo aumenta la masa muscular, sino que también es necesaria para el funcionamiento metabólico de los rumiantes (17).
En la investigación sobre ensilaje de papa se reporta un valor proteico del $12 \%$ (13), menor al conseguido en esta investigación en sus cuatro niveles de probiótico; posiblemente, esto se deba al trabajo benéfico de las bacterias lácticas en el bioensilaje, las cuales mejoran la fermentación y la actividad bacteriana, beneficiando la incorporación de las materias primas y elevando el contenido proteico. En una investigación sobre ensilaje de maíz con tres niveles de inóculos microbianos se reportan valores de proteína de $14,63 \%, 15,14 \%$ y $15,07 \%$ (18), que guardan relación con los obtenidos en la presente investigación, debido a que en las dos se establecen niveles de inóculos microbianos que influyen positivamente en la transformación de la materia prima en un bioensilaje de calidad para la producción de rumiantes, incrementando los parámetros productivos, como producción lechera diaria. En la Figura 4 se observa el análisis de regresión para proteína al utilizar niveles diferentes de probiótico. 


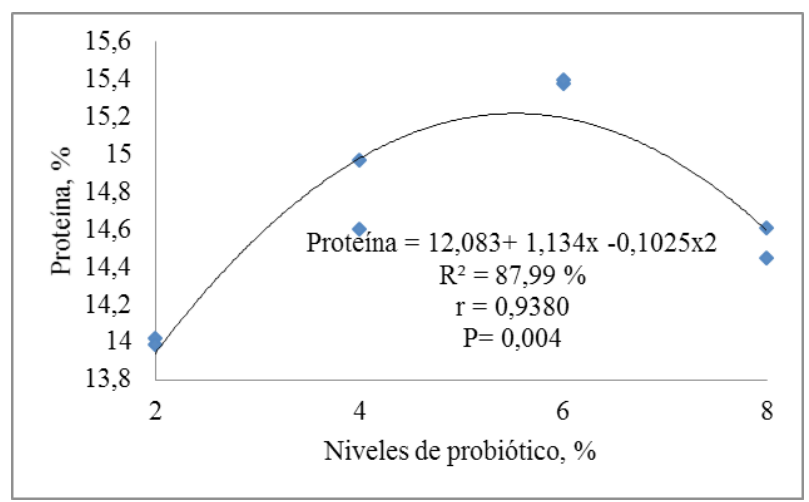

Fig. 4. Análisis de regresión para la proteína.

En el análisis de varianza para la variable fibra encontramos que existen diferencias estadísticas altamente significativas $(P<0,01)$. Con el tratamiento que utiliza el $6 \%$ del probiótico se obtuvo el $14,04 \%$, seguido por el tratamiento al $2 \%$, con un contenido en fibra de $13,66 \%$, y los tratamientos con el $4 \%$ y el $8 \%$, con porcentajes en contenido de fibra de $12,29 \%$ y $12,42 \%$; con un error estándar de $\pm 0,12$, lo cual se ilustra en la Figura 5 . Por lo tanto, se asume que el tratamiento con el 6 $\%$ de probiótico tiene el mayor contenido en fibra.

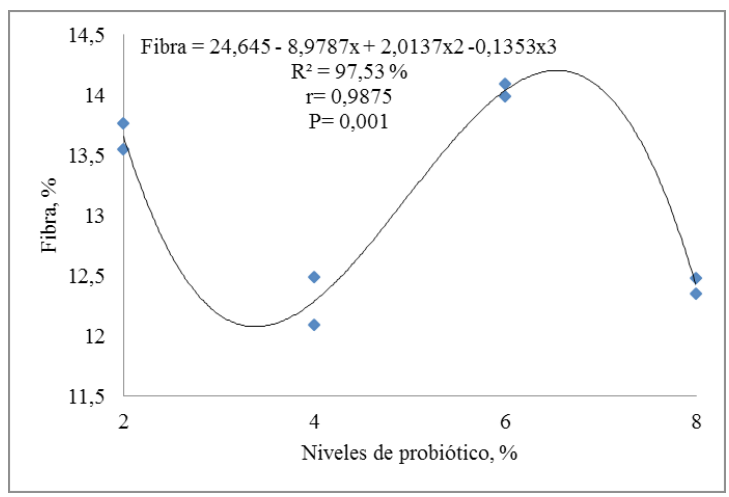

Fig. 5. Análisis de regresión para la fibra.
La fibra ayuda en el metabolismo y digestibilidad del rumiante, ya que su función es mantener un correcto funcionamiento ruminal (19); para ello, las vacas deben consumir una cantidad mínima de fibra que estimule la rumia y la salivación. Además, el contenido de fibra es un indicador útil para medir el estado de crecimiento en el cual el cultivo para ensilar se ha cosechado y para predecir la digestibilidad y el valor energético del forraje; el contenido de fibra en las materias primas depende del estado fenológico de la cosecha, es decir, a mayor edad, mayor contenido de fibra.

En la investigación citada sobre ensilaje de maíz con lacto suero se obtuvo un valor para fibra de $7,85 \%$ (20), bajo en comparación con los obtenidos en la presente investigación, y el contenido de fibra obtenido en la investigación con el ensilaje de papa (13) fue del $27,4 \%$, superior al de esta investigación; quizá esto se deba al alto contenido en almidón de la papa, que es su mayor nutrimento, bajando el contenido de hemicelulosa y lignina. En la Figura 5 se observa el análisis de regresión para la variable fibra al utilizar diferentes niveles de probiótico.

\section{Características microbiológicas del ensilaje}

Para esta variable se evidencian diferencias estadísticas altamente significativas $(P<0,01)$. Con el tratamiento del $8 \%$ de probiótico se presentan valores iniciales de 1,83E +07 UFC. $\mathrm{ml}^{-1}$, seguido por el tratamiento con el $6 \%$, que presenta el 1,63E +07 UFC. $\mathrm{ml}^{-1} \mathrm{y}$, finalmente, por los tratamientos con el $4 \%$ y el $2 \%$ de probiótico, los cuales presentan resultados de $1,48 \mathrm{E}+07$ y $9,50 \mathrm{E}+06$ UFC. $\mathrm{ml}^{-1}$, respectivamente; siendo su error estándar de 3,31E + 05 UFC. $\mathrm{ml}^{-1}$ (Tabla IX). 
Tabla IX. Análisis microbiológicos del ensilaje

\begin{tabular}{|c|c|c|c|c|c|c|c|c|c|c|}
\hline \multirow{2}{*}{ Variable } & \multicolumn{8}{|c|}{ Niveles de probiótico, \% } & \multirow{2}{*}{ E.E } & \multirow{2}{*}{ Prob. } \\
\hline & 2 & & 4 & & 6 & & 8 & & & \\
\hline $\begin{array}{l}\text { Bacterias lácticas - } \\
\text { inicio del proceso UFC. } \\
\mathrm{ml}^{-1}\end{array}$ & $9,50 E+06$ & $\mathrm{a}$ & $1,48 \mathrm{E}+07$ & $\mathrm{C}$ & $1,63 \mathrm{E}+07$ & $\mathrm{~b}$ & $1,83 \mathrm{E}+07$ & b & $3,31 E+05$ & 0,0002 \\
\hline $\begin{array}{l}\text { Levaduras -inicio del } \\
\text { proceso (UPC. } \mathrm{ml}^{-1} \text { ) }\end{array}$ & $2,93 E+05$ & $\mathrm{a}$ & $7,00 E+04$ & $\mathrm{~b}$ & $2,90 E+04$ & $\mathrm{C}$ & $1,00 \mathrm{E}+04$ & c & $3,94 \mathrm{E}+03$ & $<0,0001$ \\
\hline $\begin{array}{l}\text { Bacterias lácticas- final } \\
\text { del proceso UFC. } \mathrm{ml}^{-1}\end{array}$ & $1,75 E+08$ & $d$ & $1,86 \mathrm{E}+08$ & $\mathrm{C}$ & $2,34 \mathrm{E}+08$ & $\mathrm{~b}$ & $2,53 \mathrm{E}+08$ & a & $1,19 E+06$ & $<0,0001$ \\
\hline $\begin{array}{l}\text { Levaduras- final del } \\
\left.\text { proceso (UPC. } \mathrm{ml}^{-1}\right)\end{array}$ & $1,55 \mathrm{E}+04$ & $d$ & $2,35 E+04$ & $\mathrm{a}$ & $2,40 \mathrm{E}+04$ & $\mathrm{a}$ & $2,10 \mathrm{E}+04$ & $\mathrm{a}$ & $7,91 E+02$ & 0,0647 \\
\hline
\end{tabular}

UFC: Unidades Formadoras de Colonia

UPC: Unidades Propagadoras de Colonia

Las letras ( $a, b$ y c) muestran diferencias altamente significativas entre las medias (Tukey $\leq 0,05$ )

Al finalizar la fermentación del bioensilaje, la concentración de bacterias lácticas subió considerablemente, con diferencias estadísticas significativas. Así la mayor concentración de bacterias se tuvo con el tratamiento al $8 \%$ de probiótico, con una media de 2,53E +08 UFC. $\mathrm{ml}^{-1}$, siguiéndole el tratamiento al $6 \%$, con 2,34E +08 UFC. $\mathrm{ml}^{-1}, \mathrm{y}$ los tratamientos con el $2 \%$ y $4 \%$, que presentan resultados menores, con $1,75 \mathrm{E}+08$ y $1,86 \mathrm{E}+08$ UFC. $\mathrm{ml}^{-1}$, respectivamente; con un error estándar de $\pm 1,19 \mathrm{E}+06$ UFC. $\mathrm{ml}^{-1}$. De tal forma que el alto crecimiento de bacterias lácticas se debe a los favorables valores de $\mathrm{pH}$ bajos, que ayudan a inhibir el crecimiento de microorganismos indeseados y favorecen el crecimiento de microorganismos benéficos, lo cual se muestra en la Figura 6.

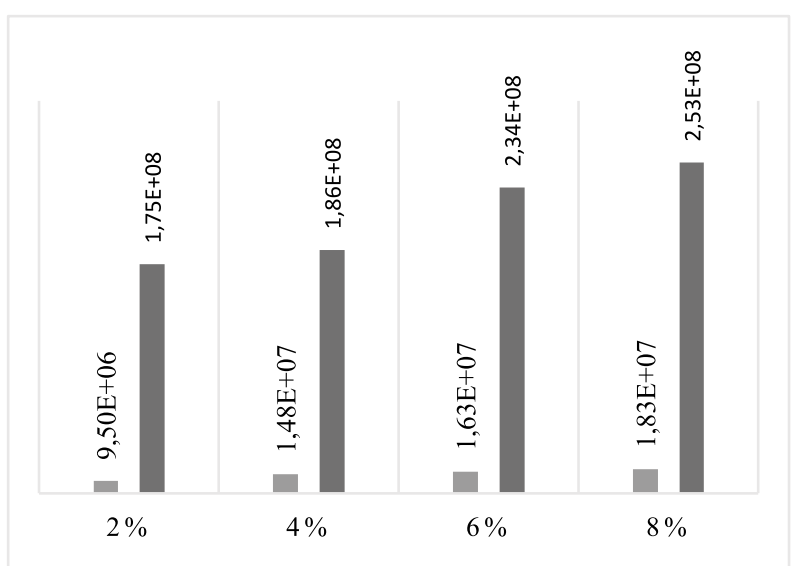

Fig. 6. Evaluación del crecimiento de bacterias ácido-lácticas (UFC. $\mathrm{ml}^{-1}$ )
El éxito del proceso fermentativo al que son sometidos los ensilajes depende, principalmente, de una cantidad suficiente de bacterias ácido-lácticas y de una concentración apropiada de carbohidratos solubles en el forraje que genera el ácido láctico (21), y así, el pH se mantiene bajo y el ensilaje se conserva en buenas condiciones. La investigación acerca de ensilaje de maíz en clima frio obtiene resultados de 2,0E $+06 \mathrm{UFC} \cdot \mathrm{ml}^{-1}$ al inicio de la fermentación (22), valores cercanos a los obtenidos en esta investigación, y al final obtiene 3,1E +09 UFC. $\mathrm{ml}^{-1}$, resultado superior al de nuestra investigación. El análisis de regresión para la bacterias ácido-lácticas se puede observar en la Figura 7.

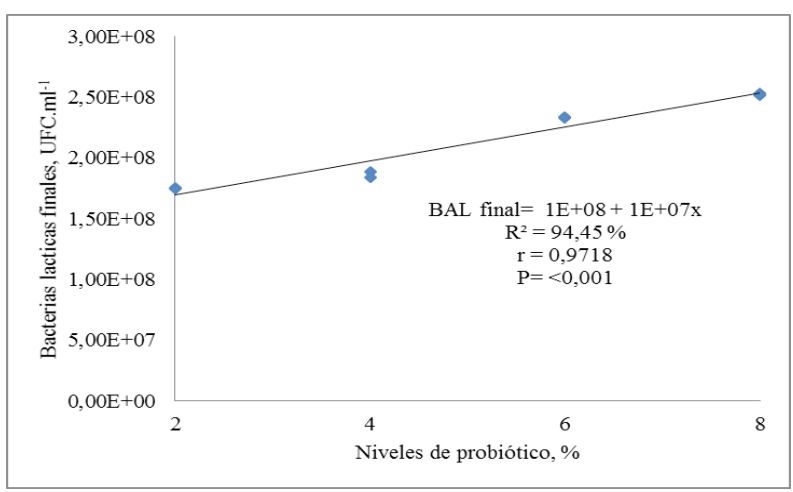

Fig. 7. Análisis de regresión para bacterias ácidolácticas.

En el trabajo sobre ensilaje de maíz forrajero con inoculantes bacterianos se reportan resultados de $9,43+04$ UFC. $\mathrm{ml}^{-1}(23)$, por lo que el ensilaje de nuestra investigación tiene mayor concentración 
de bacterias lácticas, que ayudan a inhibir el crecimiento de patógenos.

Según el análisis de varianza, la variable levadura muestra una diferencia estadística alta $(\mathrm{P}<0,05)$. Al inicio del proceso se obtuvo una concentración de $2,93 \mathrm{E}+05$ UPC. $\mathrm{ml}^{-1}$ con el tratamiento del $2 \%$ de probiótico, y para los tratamientos con $4 \%, 6 \%$ y $8 \%$ se obtuvieron concentraciones de $7,00 \mathrm{E}+04$, $2,90 \mathrm{E}+04$ y $1,00 \mathrm{E}+04$ UPC. $\mathrm{ml}^{-1}$, respectivamente;

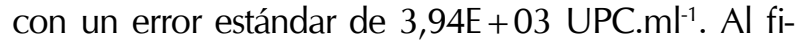
nal de la investigación no se presentan diferencias altamente significativas ( $\mathrm{P}>0.05)$; es así como en el tratamiento $2 \%$ las concentraciones de levaduras son $1,55 \mathrm{E}+04$ UPC. $\mathrm{ml}^{-1} \mathrm{y}$ en los tratamientos $4 \%, 6 \% \mathrm{y}$ $8 \%$ son de $2,356 \mathrm{E}+04 ; 2,40 \mathrm{E}+04$ y $2,10 \mathrm{E}+04 \mathrm{UPC}$. $\mathrm{ml}^{-1}$, en su orden, con un error estándar de $7,91 \mathrm{E}+02$ UPC. $\mathrm{ml}^{-1}$; el crecimiento de levaduras desciende en cuanto aumenta el porcentaje de probiótico, lo cual se ilustra en la Figura 8.

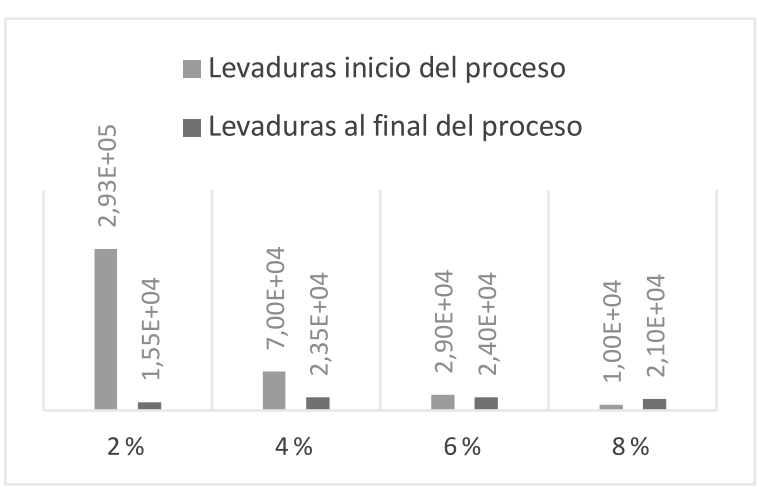

Fig. 8. Evaluación del crecimiento de levaduras.

El crecimiento de estos microorganismos se debe principalmente a que viven de manera natural en los alimentos y forrajes, y a que tienen la capacidad de desarrollarse más fácilmente a temperaturas ba- jas, en un rango entre $0^{\circ} \mathrm{C}$ y $30^{\circ} \mathrm{C}$, con valores ideales cercanos a los $20^{\circ} \mathrm{C}$ (con algunas excepciones) y con humedades ambientales mayores al $80 \%$; es, por lo tanto, posible que las condiciones ambientales en que se cultivó el forraje hayan sido favorables para el crecimiento de estos microorganismos. En una investigación sobre ensilaje de maíz se cita un crecimiento de levaduras del orden de 9,0E + 06 UPC. $\mathrm{ml}^{-1}$ (24), mientras que (22), en su estudio microbiológico y de calidad nutricional del ensilaje de maíz cosechado en dos ecorregiones de Colombia, obtiene valores iniciales de 2,4E + 07 UPC. $\mathrm{ml}^{-1}$ y 2,0E + 04 UPC. $\mathrm{ml}^{-1} \mathrm{a}$ los 28 días de fermentación, los cuales son similares a los de esta investigación.

El análisis de regresión para el contenido de levaduras por efecto de los diferentes niveles de probiótico aplicados en el bioensilaje se representa en la Figura 9.

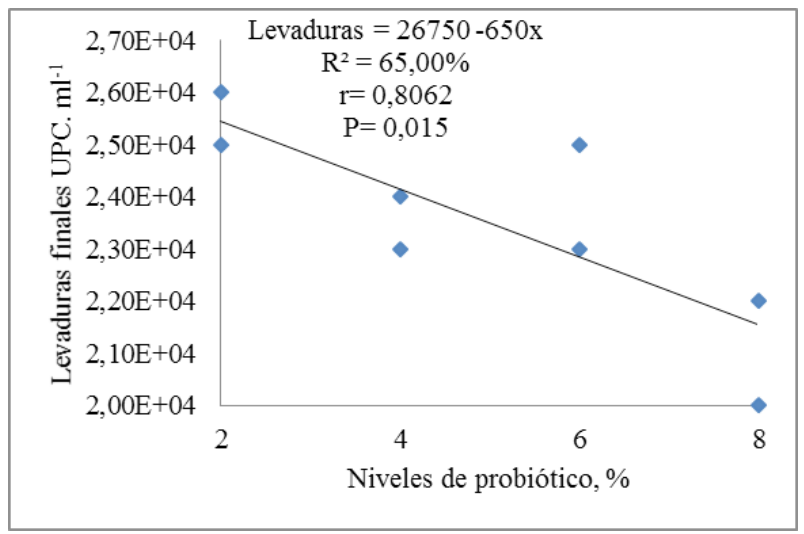

Fig. 9. Análisis de regresión para levaduras.

En la Tabla X se observan los resultados obtenidos del ensilaje para patógenos tanto al inicio como al final del proceso de fermentación del bioensilaje.

Tabla X. Resultados microbiológicos para patógenos al final del proceso de bioensilaje

\begin{tabular}{|c|c|}
\hline Indicador & Resultado \\
\hline Microbiológicos UFC.ml ${ }^{-1}$ & \\
\hline E. Coli & Ausencia \\
\hline Salmonella, sp & Ausencia \\
\hline Clostridium & Ausencia \\
\hline Microbiológicos UPC. $\mathbf{m l}^{\mathbf{1}}$ & \\
\hline Mohos & Ausencia \\
\hline
\end{tabular}


La norma INEN 1829, para alimentos zootécnicos, establece que debe haber ausencia de Salmonella sp. y un máximo de $1 \times 10^{4}$ UFC.ml- ${ }^{-1}$ de E. Coli y de $1 \times 10^{4}$ UPC. $\mathrm{ml}^{-1}$ de hongos; por ende, se puede afirmar que el ensilaje de nuestra investigación es apto para el consumo de rumiantes, ya que al no existir estos patógenos los animales no corren riesgo de infección. Tampoco existe la presencia de Clostridium sp., microorganismo que, según (19), al presentarse durante la fermentación del ensilaje causa pudrición y una forma de envenenamiento al animal que lo consume y que incluso es un riesgo para la salud humana.

\section{E. Análisis de producción de leche}

Según el análisis de varianza para la variable producción de leche en vacas Holstein, no se encontraron diferencias estadísticas significativas $(p>0.05)$ por efecto del bioensilaje de zanahoria con niveles diferentes de probiótico; aun así, se mostraron diferencias numéricas por efecto de la suplementación a base de bioensilaje con diferentes niveles de preparado microbiano nativo, resaltándose el tratamiento con el $6 \%$, con una producción inicial de 14,08 L y, finalmente, de 17,40 L a los 22 días de aplicado el tratamiento, es decir, un aumento en la producción de 3,32 $\mathrm{L}$ de leche, es decir el 23,5\%. A este le sigue el tratamiento con el $4 \%$, el cual inicia con $13,27 \mathrm{~L}$ y finaliza con 15,64 , con lo que se tiene un aumento en la producción de $2,37 \mathrm{~L}$, lo cual representa un $17,85 \%$; en tanto que el ensilaje con el $8 \%$ de probiótico sería el que menos efecto tiene en el ganado, apenas con un aumento en los 22 días de tratamiento de $0,23 \mathrm{~L}$, lo cual representa el 1,66 \%; entonces podemos decir que el bioensilaje de zanahoria sí influye en la producción de leche (Tabla XI).

Tabla XI. Producción de leche en vacas alimentadas con el bioensilaje

\begin{tabular}{|c|c|c|c|c|c|c|c|c|c|c|c|c|}
\hline \multirow[b]{2}{*}{ Variable } & \multicolumn{10}{|c|}{ Niveles de probiótico, \% } & \multirow[b]{2}{*}{ E.E } & \multirow[b]{2}{*}{ Prob. } \\
\hline & 0 & & 2 & & 4 & & 6 & & 8 & & & \\
\hline Producción inicial, L & 12,94 & $\mathrm{a}$ & 13,34 & $\mathrm{a}$ & 13,27 & a & 14,08 & $\mathrm{a}$ & 13,78 & $\mathrm{a}$ & 1,78 & 0,9666 \\
\hline Producción 7 días, L & 12,82 & $\mathrm{a}$ & 13,13 & $\mathrm{a}$ & 13,51 & $\mathrm{a}$ & 15,93 & a & 13,58 & a & 1,98 & 0,6834 \\
\hline Producción 15 días, L & 12,06 & a & 12,70 & $\mathrm{a}$ & 14,38 & $\mathrm{a}$ & 16,39 & a & 13,52 & a & 1,93 & 0,4387 \\
\hline Producción 22 días, $\mathrm{L}$ & 11,80 & a & 14,14 & $\mathrm{a}$ & 15,64 & a & 17,40 & a & 14,01 & $\mathrm{a}$ & 2,32 & 0,4183 \\
\hline
\end{tabular}

Letras distintas $(a, b$ y $c)$, muestran diferencias altamente significativas entre las medias (Tukey $\leq 0,05)$

Se evidencia que los preparados microbianos mejoran notablemente la asimilación de nutrientes y estimulan el apetito (25), favoreciendo el bienestar del animal y haciéndolo menos propenso a enfermedades entéricas; todo este conjunto mejora los parámetros productivos, principalmente, en vacas lecheras, que mantienen la condición corporal con incremento de la producción lechera (25). Un ensayo con la utilización de bioensilajes agroindustriales en la alimentación de vacas lecheras inició con una producción de 25 L.día $^{-1}$, y al utilizar ensilaje de maíz disminuyó a 18,52 L.día-1 (26), lo cual puede deberse a que este bioensilaje se halla enriquecido con suero de leche y estiércol bovino. El bioensilaje de zanahoria es mejor, debido a que promueve un aumento en la producción del 23,5 \% con el mejor tratamiento ( $6 \%$ de probiótico). Se sostiene que, al iniciar la lactancia, las vacas lecheras se enfrentan a un transporte masivo de lípidos, proteínas y lactosa a la glándula mamaria, lo cual en términos de energía representa de dos a tres veces sus requerimientos de mantenimiento, para vacas con producciones de 20 a $25 \mathrm{~L} . d i a^{-1}$ (27). Considerando que en este período fisiológico todo el organismo es un complemento de la glándula mamaria, guiando la actividad de otros tejidos y órganos para sostener la producción láctea, el uso único de ensilaje de zanahoria no cubre las necesidades totales de un rumiante para la producción.

\section{F. Análisis económico: Relación beneficio/costo}

En la Tabla XII se presentan los costos en cada uno de los tratamientos y durante el proceso productivo de vacas lecheras, representados por los rubros consumo de ensilaje, consumo de balanceado, análisis de laboratorio, transporte y mano de obra, en tanto que los ingresos estuvieron representados por precio de la leche y venta de la vaca. 
Tabla XII. Análisis económico para determinar el beneficio costo del uso de bioensilaje en vacas lecheras

\begin{tabular}{|c|c|c|c|c|c|c|c|}
\hline \multirow[b]{2}{*}{$\begin{array}{l}\text { Rubro } \\
\text { Insumos }\end{array}$} & \multirow{2}{*}{ Unidad } & \multirow{2}{*}{$\begin{array}{c}\text { Costo, } \\
\$\end{array}$} & \multicolumn{5}{|c|}{ Bioensilaje con diferentes niveles de probiótico, \% } \\
\hline & & & T0 $(0 \%)$ & $\mathrm{T} 1(2 \%)$ & $\mathrm{T} 2(4 \%)$ & T3 $(6 \%)$ & T4 $(8 \%)$ \\
\hline Número de vacas & unidad & & 2 & 2 & 2 & 2 & 2 \\
\hline Vacas & unidad & 400 & 800 & 800 & 800 & 800 & 800 \\
\hline Balanceado & $\mathrm{kg}$ & 0,45 & 28,35 & & & & \\
\hline Follaje de zanahoria & $\mathrm{kg}$ & 0,01 & & 0,22 & 0,22 & 0,22 & 0,22 \\
\hline Zanahoria & $\mathrm{kg}$ & 0,06 & & 3,96 & 3,96 & 3,96 & 3,96 \\
\hline Afrecho de trigo & $\mathrm{kg}$ & 0,31 & & 6,82 & 6,82 & 6,82 & 6,82 \\
\hline Probiótico & $\mathrm{L}$ & 0,69 & & 1,52 & 3,04 & 4,55 & 6,07 \\
\hline Bolsas de ensilaje & unidad & 0,25 & & 1,50 & 1,50 & 1,50 & 1,50 \\
\hline \multicolumn{8}{|l|}{ Manejo } \\
\hline $\begin{array}{l}\text { Análisis de labora- } \\
\text { torio }\end{array}$ & unidad & 39,49 & & 39,49 & 39,49 & 39,49 & 39,49 \\
\hline Recipientes & unidad & 0,1 & & 0,20 & 0,20 & 0,20 & 0,20 \\
\hline Transporte & unidad & 12,5 & 12,50 & 12,50 & 12,50 & 12,50 & 12,50 \\
\hline Mano de Obra & jornal & 350 & 70,00 & 70,00 & 70,00 & 70,00 & 70,00 \\
\hline EGRESOS & & & 910,85 & 936,21 & 937,73 & 939,24 & 940,76 \\
\hline Venta de las vacas & unidad & 400 & 800 & 800 & 800 & 800 & 800 \\
\hline Producción de leche & $\begin{array}{l}\text { L / } 21 \\
\text { días }\end{array}$ & & 260,48 & 279,87 & 298,21 & 334,952625 & 288,17625 \\
\hline Precio & $\mathrm{L}$ & 0,35 & 91,17 & 97,95 & 104,37 & 117,23 & 100,86 \\
\hline Ingresos & & & 1151,64 & 1177,83 & 1202,59 & 1252,19 & 1189,04 \\
\hline Beneficio.costo $^{-1}$ & & & 1,26 & 1,26 & 1,28 & 1,33 & 1,27 \\
\hline
\end{tabular}

Así, la mayor rentabilidad para la producción de leche mediante la suplementación alimenticia de vacas lecheras se obtiene con el $6 \%$ de probiótico en el ensilaje de zanahoria, con un beneficio/costo de 1,33 USD, lo que se traduce en una rentabilidad de 0,33 USD, por cada dólar invertido en el proceso de producción.

\section{Conclusiones}

Los residuales de zanahoria amarilla presentan $90,20 \%$ de humedad, 7,16\% de proteína y 7,40 $\%$ de fibra, en tanto que su follaje presenta 10,53 $\%$ de proteína, $14,74 \%$ de fibra y $16,49 \%$ de materia seca. En tanto que el suero fresco de leche contiene $0,7 \%$ de proteína y $0,55 \%$ de grasa.
Las características físico-químicas del proceso de bioensilaje a partir de residuales de zanahoria fueron: $\mathrm{pH}$ de 3,9 y temperatura de $19{ }^{\circ} \mathrm{C}$.

Los componentes bromatológicos del bioensilaje difieren estadísticamente $(P<0,001)$ entre tratamientos, siendo mayor el contenido de proteína, fibra y humedad, con $15,39,14,04$ y $74,78 \%$, respectivamente, con el empleo del $6 \%$ de preparado microbiano nativo.

La cantidad de bacterias ácido-lácticas fue mayor con el nivel de $8 \%$ de probiótico, con 92,53E + 08 UFC. $\mathrm{ml}^{-1}$ y ausencia total de patógenos como Salmonella sp., Clostridium sp., E. coli y mohos en todos los tratamientos. 
Las características organolépticas referentes a color, olor y sabor del bioensilaje en los cuatro tratamientos fueron buenas, demostrándose buena palatabilidad en el ganado lechero evaluado.

Se incrementó la producción de leche en vacas Holstein mestizas con el tratamiento que utiliza el $6 \%$ de preparado microbiano nativo como parte del bioensilaje, ya que se observó un aumento de 14,08 litros.día ${ }^{-1}$ a 17,40 litros.día ${ }^{-1}$.

El análisis económico determinó que con el bioensilaje de zanahoria con el $6 \%$ de probiótico se obtiene mayor rentabilidad, estableciéndose un índice de beneficio.costo ${ }^{-1}$ de 1,33.

El bioensilaje de zanahoria debe considerarse un suplemento alimenticio; se sugiere utilizar aquel con la adición del $6 \%$ de probiótico, ya que presenta los mejores resultados en contenido de proteína y producción lechera.

Realizar análisis químico de la leche, ya que este alimento podría modificar su composición nutricional, así como las características físico-químicas y organolépticas.

Se recomienda investigar la utilización de este bioensilaje en otros rumiantes y en diferentes estadios de la producción y en períodos más largos de tiempo.

\section{Agradecimientos}

A la ESPOCH, Facultad de Ciencias Pecuarias, Laboratorio de Biotecnología animal, por las facilidades prestadas con sus instalaciones y equipos para el desarrollo de esta investigación.

Conflicto de intereses: No existe conflicto de intereses de ninguna índole entre los autores de este trabajo.

\section{Referencias}

(1) Almeida-Borja P., Zambrano Vidal M. Elaboración de jugo, pasta y polvo de zanahoria. Tesis de Grado. Escuela de Ciencias, Escuela Politécnica Nacional, Quito, Ecuador. 2007.

(2) AOAC. Official Methods of Analysis. 16th Ed. Ass. Off. Anal. Chem. Washington, D.C. 1995.
(3) Petrifilm 3M. 2005. Técnicas estandarizadas de microbiología de alimentos. 2005. Disponible en: http://www.3m.com/petrifilm.

(4) INEC. Encuesta de superficie y producción agropecuaria continúa ESPAC - Ecuador. 2011. Disponible en: http://www.inec. gob.ec/espac_publicaciones/espac2011/informe_ejecutivo $\% 20$ 2011.pdf.

(5) Noboa T. Caracterización fermentativa, bioquímica y microbiológica de un preparado microbiano nativo con potencial uso en animales domésticos. Tesis de Grado, Facultad de Ciencias Pecuarias, Escuela Superior Politécnica de Chimborazo, Riobamba, Ecuador. 2015.

(6) Minson D. Effects of chemical and physical composition of herbage esten upon intake in Nutritional Limits to Animal Production. Hacker., Queensland, Australia. En: Proc. Int Symp. St. Lucia. 2001.

(7) Calvache García I. Factores que influyen en la composición nutricional de la leche. Rev. Cienc. Anim, 2012; 20 (5): 73-85.

(8) Lovato J. Determinación de residuos de antibiótico, sulfonamidas y control de calidad en leche cruda provenientes de tres cantones de la provincia de Chimborazo. Tesis de Grado, Facultad de Ciencias Pecuarias, Escuela Superior Politécnica de Chimborazo, Riobamba, Ecuador. 2012.

(9) Vega Montero G. Elaboración y control de calidad de una bebida a base de suero de leche y avena para Productos el Salinerito. Tesis de Grado, Facultad de Ciencias, Escuela Superior Politécnica de Chimborazo, Riobamba, Ecuador. 2016.

(10) Gil Hernández A. Tratado de nutrición: Composición y calidad nutritiva de los alimentos. $2^{\text {a }}$ ed. Buenos Aires, Argentina, Médica Panamericana: 152-155. 2010.

(11) Jiménez F., Moreno J. El ensilaje. 2002. Corpoica, Colombia. Disponible en: https://goo.gl/TegjuU.

(12) Loor Urdanigo J. Efecto de la aplicación de inoculantes bacterianos en la composición química y fermentativas de ensilados de maíz forrajero (zea mays I.). Tesis de Grado, Facultad de Ciencias Pecuarias, Universidad Estatal de Quevedo, Ecuador. 2013.

(13) Ruiz Ortiz J. Evaluación de la producción y calidad de la leche en vacas Holstein de primer parto suplementadas con ensilaje de papa. Tesis de Maestría, Facultad de Zootecnia, Universidad de Lasalle, Colombia. 2006.

(14) Balza K., Barrios K. Utilización de los residuos de lechuga para ensilaje como alternativa en la alimentación de bovinos. Tesis de Maestría, Universidad de Santa María, Caracas, Venezuela. 2014.

(15) Vallejo F., Estrada E. Producción de hortalizas de clima cálido. Universidad Nacional de Colombia. 2004.

(16) Guerra Espinoza F., Montenegro B. Efecto de inoculantes microbianos sobre las características químicas y fermentativas de ensilajes de maíz forrajero. Tesis de Grado, Facultad de Ciencias Pecuarias, Universidad Técnica Estatal de Quevedo. 2015.

(17) Mellado M. Producción de leche en zonas templadas y tropicales. México DF, México, Trillas. 2010.

(18) Cubero J., Rojas A., Wingching W. Uso del inóculo microbial elaborado en finca en ensilaje de maíz (zea mays). Valor nutri- 
cional y fermentativa. Agronomía Costarricense. 2010; 34 (2): 237-250.

(19) Chaverra G., Bernal E. El ensilaje en la alimentación del ganado vacuno. Venezuela: IICA. 2001.

(20) Tene Chamba D. Ensilado de maíz con adición de lactosuero y microorganismos eficientes, en el cantón Paltas. Tesis de Grado, Área Agropecuaria y de Recursos Naturales Renovables, Universidad Nacional de Loja, Ecuador. 2015.

(21) Tobía. Aislamiento, selección y caracterización de bacterias ácido lácticas en ensilajes de soya. Agronomía Costarricense. 2003; 27(2): 21-27.

(22) Villa Lenis A. Estudio microbiológico y calidad nutricional de ensilaje de maíz cosechado en dos ecorregiones de Colombia. Tesis de Maestría, Facultad de Medicina Veterinaria y de Zootecnia, Universidad Nacional de Colombia, 2008.

(23) Narváez Aranda D. Efecto de la aplicación de inoculantes sobre las características microbianas a los 60 días de ensilaje de maíz forrajero (Zea mayz). Tesis de Grado, Facultad de Ciencias Pecuarias, Universidad Técnica Estatal de Quevedo, Ecuador. 2013.

(24) FAO. Los procesos de fermentación del ensilaje y su manipulación. 2000. Disponible en: http://www.fao.org/3/contents/5645cc42-5f28-579c-a4fc-4fb17e92014c/x8486s04.htm.

(25) Milian G. Empleo de probióticos a base de Bacillus sp. y sus endosporas en la producción avícola. Instituto de Ciencia Animal, La Habana, Cuba. 2005.

(26) Salazar Álvarez L. Evaluación "in vivo" de ensilaje de residuos agroindustriales y biológicamente acelerados en vacas lecheras. Tesis de Grado, Facultad de Ciencias Pecuarias, Escuela Superior Politécnica de Chimborazo, Riobamba, Ecuador. 2007.

(27) Avalos Zambrano J. Inclusión de afrecho de maíz duro en la alimentación de vacas Holstein mestizas de la estación experimental TUNSH. Tesis de Grado, Escuela Superior Politécnica de Chimborazo, 2015. 
